\title{
XLIII. Note on the genus Condylura of Illiger
}

\section{J.D. Godman M.D.}

To cite this article: J.D. Godman M.D. (1826) XLIII. Note on the genus Condylura of Illiger , Philosophical Magazine Series 1, 67:336, 273-277, DOI: 10.1080/14786442608674056

To link to this article: http://dx.doi.org/10.1080/14786442608674056

曲 Published online: 10 Aug 2009.

Submit your article to this journal $\pi$

Џll Article views: 3

Q View related articles $\sqsubset$ 


\section{Note on the Genus Condylura of Illiger. By J. D. Godman, M.D.**}

A $S$ several very interesting external characters peculiar to $A$ the Condylura cristata have been entirely overlooked by those who have heretofore written on this subject, the object of this Note is to supply the deficiency as far as possible, especially as these characters may be very serviceable in enabling us to compare the present genus with some others.

The Condylura cristata is destitute of an auricle projecting above the level of the skin, but is, nevertheless, provided with an extremely large external ear, as we may properly consider all that part which is entirely exterior to the tympanum and skull. The meatus externus is half an inch long, having a distinctly marked tragus and anti-tragus, and is situated at a short distance from the shoulder, in the broad triangular fold of integument connecting the fore-arm and head, and may be very easily missed by those who merely examine stuffed skins, or specimens preserved in spirits. From the meatus; the course of the cartilaginous tube is obliquely downwards, forwards, and inwards, until it terminates in a delicate bony tube, previous to reaching the tympanum, which is large and composed of a very delicate membrane.

The scales on the anterior and posterior extremities have been mentioned in general terms by several writers, especially by Desmarest, who has given the best description of the animal that has yet appeared. But these scales are so peculiar and uniform in their position, that I cannot understand how a naturalist could pass over the particulars of their arrangement in silence.

On the anterior extremities the superior or ulnar edge of the hand has on its anterior surface, (regarding the position of the animal,) a row of corneous scales, about nine in number, which are broadest midway from the carpus to the first phalanx of the fifth finger. Another row of scales commences on the inferior part of the back of the little finger, becoming broader and of a semilunar figure as they extend towards the metacarpus, between these two a much smaller row is placed. The fourth finger has a single row of small scales on its upper posterior side, and a large one extending along the back of the finger to the metacarpus; the middle finger has a small central row, which is distinguishable; that on the fore finger is still more faint ; the thumb has none but very small ones on its central posterior part, but on its inferior posterior part, or

- From Journal of Acad. of Nat. Sciences of Philadelphia, vol. v. p. 109.
Vol.67. No. 396. April 1826.
$2 \mathrm{M}$
radial 


\section{Dr. Godman's Note on the Genus Condylura of Illiger.}

radial edge, it has one scale of considerable size on the phalanx, and four or five between this part and the carpus; the two nearest the scale on the phalanx are largest.

The surface of the palm of the hand is covered with small circular scales, extending most numerously, and of a darker colour, from opposite the root of the thumb obliquely outward to the basis of the little finger.

On the inferior extremities, the whole of the superior surface of the foot is covered with minute, blackish, circular scales, which increase slightly in size as they approach the toes. On the anterior part of the fourth toe is a large central row of black scales, and on the fifth a rather smaller one; hence these toes have a very considerable resemblance to the toes of a bird. The other toes of the hind foot being applied with their anterior surfaces to the ground, have the scales very minute and almost colourless.

The colour of the scales varies on different parts of the hand. On so much of the back of the hand as is formed by the fourth and little fingers, the scales are very dark blue, approaching a black, in the living animal; thence to the large scales of the thumb the colour changes to a faint purplish blue, which is little more than distinguishable.

Two other excellent characters belonging to the palm of the hand have been neglected: the first is the enlargement of the carpal edge of the palm by an elongation of the integuments; this, in addition to the row of bristles that margins all the rest of the palm, has two distinct bristly hairs at its superior and inferior edge, more than $\frac{1}{8}$ th of an inch long. The second character is still more striking; it is a process of the palmar cuticle on the superior edge of the thumb and three succeeding fingers. These processes are serrated and directed obliquely upwards and outwards; the serrations on the thumb being two, and on the three succeeding fingers three in number.

On the soles of the (posterior) feet another character is found, which consists of five circular, distinct spots, so arranged that the two nearest the body are parallel with each other, opposite the commencement of the first toe, counting as in the human subject, from the one nearest the median line of the body; the superior spot is nearly in a line with the fourth toe, and larger and darker coloured than the inferior; the two succeeding spots (nearer the extremity of the toes) are also parallel with each other; the exterior one is largest of all these plantar scales, and placed nearly over the extremity of the metatarsal of the fourth toe; the inferior spot is nearly over the root of the second toe; the fifth or single scale is placed in advance of all the rest, and is situated immediately 
over the centre and behind the separation of the third and fourth toes.

A very analogous arrangement may be observed in the sole of the feet of the Sigmodon hispidum of Ord.

By comparing the Condylura with the Scalops, we are led to several interesting observations. We have seen that the Condylura has a remarkable and large external ear, though it is destitute of a projecting auricle. The Scalops has neither auricle nor meatus externus opening on the side of the head, as the skin of the head extends over the cartilaginous tube, which is small, and a simple funnel. The situation of the ear is to be discovered externally only by a very small spot, not larger than the circumference of an ordinary pin head.

The hand of the Scalops is peculiar for its great breadth and strength: the extraordinary breadth is produced by an additional metacarpal bone, inferior or external to the thumb, articulated with the carpus, and having a tendon for moving it from the common flexor of the fingers*. On the superior or ulnar edge of the hand there is a cartilaginons additament, connected with the little finger by a tendon. The Condylura has the additional metacarpal bone, but rather like a rudiment, and has not the cartilaginous additament at the superior edge of the hand; hence the very great difference in breadth in the hands of the two genera. The Scalops has a slight process or elongation, not at the carpal extremity of the palm, but on the inferior or outer edge of the supplementary bone.

If we compare the Scalops and Condylura with the description of Talpa europae, the resemblance will be found greater between the Condylura and Talpa in regard to the ears and eyes. If we compare the hands and nose, we shall find that the Scalops approximates more closely to the European genus; nevertheless, the affinity of neither is so strong as to endanger their being confounded with Talpa, if we were to judge from external characters alone + .

Of the genus Condylura I balieve after a patient examination, and obtaining specimens from various localities, that most probably there is no other species in this country than

* This structure resembles that of the Talpa europea; but as that species does not exist in this country, I have not been able to obtain a recent specimen for comparison.

I I am happy to state from actual and repeated observation, that it is the Scalops which in this country forms the "mole-hills," similar to those thrown up by the Talpa europaa. As far as I can ascertain, no such circumstance has yet been remarked relative to the burrowing of the Condylura. In a forthcoming work on American Natural History, a full account will be given of my observations on the habits of the Scalops and Condylura. 


\section{Dr. Godman's Note on the genus Condylura of Illiger.}

the cristata*. The only evidence of the existence of a longicaudata is that given by Pennant, who aescribes it without reference to the nasal rays. It is on this indication that Gmelin, Illiger, and Desmarest have allowed of the species, the latter author with very strong doubts, which Ranzani repeats. . From Pennant's figure I feel convinced that his longicaudata was a stuffed and dried specimen of the Condylura cristata, having the nasal radii shrunk and distorted. A specimen in this condition $I$ have now in my possession, and it might readily be taken for the longicaudata, figured by Pennant.

The Condylura cristata is subject at certain seasons to a very remarkable enlargement of the tail, varying from the smallest or most ordinary size to the thickness of the little finger. This circumstance was long since made known to many of his friends by Mr. Titian Peale, who found one of the largest size: since then $I$ have found one, and examined several others, and both Messrs. Say and Bonaparte confirm this observation by other examinations : all the specimens yet examined having the tail thus enlarged, were males; and it is most probable that the enlargement occurs only during the rutting season. Messrs. Say and Peale both suggested to me a long time since, that the differences heretofore serving for the establishment of the longicaudata: as a distinct species, were merely sexual. In all other respects the species of Condylura found are invariable in their externat characters, if we except a single specimen obtained by my friend, Titian Peale, which may prove to be a new species, should he find other specimens with the same character, for which purpose he defers his observations: It is certainly an extremely desirable circumstance that we should rid the American Fauna of a great number of merely nominal species, which never had existence unless in the imagination of their authors: to this end the labours of American naturalists should be directed, as it is a great advance towards true knowledge to disencumber ourselves of error.

It is well known that the appearance from which Illiger named the genus, was an extravagant exaggeration of Delafaille, who represented it in his plate as having numerous knots or strangulations on the tail. Desmarest's figure is also incorrect in relation to the tail; he having figured it from a

- A late number of the United States Literary Gazette contained an annunciation of a newly discovered species of this genus, by Dr. Harris, of Milton. From a description given by this gentleman in a letter to a distinguished naturalist of Philadelphia, we are satisfied that the supposed new animal is the well known Condylura cristata. 
dried specimen; in the recent state, the knotted appearance is not distinguishable: he has also drawn it with the palms turned nearly to the earth, instead of placing them with the thumbs to the ground and the palms presenting backwards. In the recent English translation of Baron Cuvier's Règne Animal, Dèsmarest's figure is copied, but is rendered vastly more incorrect and unnatural than it is in the original.

Note.-In my Note on the genus Condylura recently published, it is stated that the Scalops has the integuments continued over the cartilaginous tube leading to the internal ear. I lately had an opportunity of examining several fine specimens, and have found the very small meatus auditorius externus, which will admit a body of the size of a common pin. It is by no means easily discovered, and is situated about three-fourths of an inch behind the eye, nearly over the anterior part of the shoulder joint.

XLIV. On the Opposition of the Minor Planets. By Stephen GroombridGe, Esq. F.R.S. \&c. \&c.

HAVING computed the apparent places of these planets about the time of their respective oppositions in preceding years, from elements which required correction in the mean epoch of longitude on the orbit; particularly in Pallas, whose mean diurnal tropical motion had been assumed too great a quantity : I have now corrected their elements from the observations made at Greenwich in the last year; and the following Ephemeris will show their apparent places at midnight for 1826.

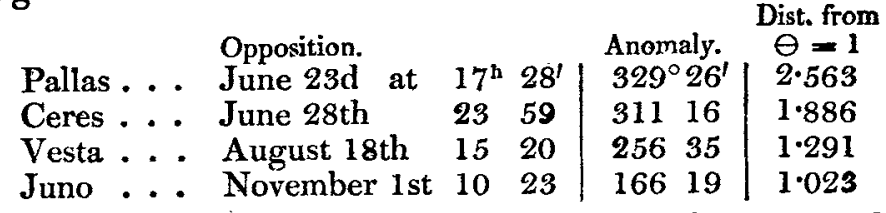

Pallas will appear very faint, being so distant from the earth; but Vesta and Juno being in the lower part of their orbits, will appear as stars of 6 th and 7 th magnitude.

Blackheath, April 19, 1826.

S. GroombridGe. 